\title{
Assessment of the Immediate and Potential Long-Term Effects of COVID-19 Outbreak on Socioeconomics, Agriculture, Security of Food and Dietary Intake in Nigeria
}

\author{
Abiodun Elijah Obayelu ${ }^{1} \cdot$ Oluwakemi Adeola Obayelu $^{2} \cdot$ Kamilu Kolade Bolarinwa $^{3}$. \\ Richard Akinwumi Oyeyinka ${ }^{3}$
}

Accepted: 24 February 2021 / Published online: 18 March 2021

(C) The Author(s), under exclusive licence to Springer Nature Switzerland AG 2021

\begin{abstract}
Nigeria agriculture, food security and dietary intake have not been exempted from the disruptions in countless sectors around the world due to the outbreak of COVID-19. The country first experienced the outbreak on February 27, 2020, and the experience since then has shown negative effects not only on the socioeconomic conditions but also on agriculture, food security and dietary intake. Long term in-depth analysis of the effects of this pandemic on food security and dietary intake using quantitative data is still very difficult due to paucity of data and the great level of the improbability of the trajectory of the spread of the Virus. This study is a rapid assessment of the short and long-term potential effects of the disease. It relied on a review of situation reports especially by the Nigeria Centre of Disease Control and other reports around the world on COVID-19, personal observations, and public opinion via mobile telephone survey of Lagos and Oyo States, Nigeria. Findings show that food demand and supply shocks caused by COVID-19 outbreak affect agriculture, food and dietary intake negatively through COVID-19 policies. It leads to a reduction in household income coupled with hike in food prices. Owing to the Nigeria's crude farming practice, there was a scarcity of hired labour required for production process during 2020 farming season. This implies a high likelihood of low output and further surge in food prices in the future. Food access was also compromised with the accumulation of unsold fresh produce by the smallholder farmers and the low salary earners during movement restrictions and of loss income as a result of international border closure. Food and dietary intake is affected as people are shifting diets to more affordable and low quality foods, while food stability is not guaranteed due to market insecurity, prompting an extraordinary level of indecision. The study concludes that the shock of COVID-19 is not only a demand management problem but a multidimensional crisis requiring monetary, fiscal, and health policy responses with global collaboration and cooperation.
\end{abstract}

Abiodun Elijah Obayelu obayelu@yahoo.com

Extended author information available on the last page of the article 
Keywords Income losses · Global economic recession · COVID-19 hunger · COVID-19 lockdown $\cdot$ Food security crisis

\section{Introduction}

Every disease affects not only people's health but comes with direct or indirect effects on the socioeconomic status, agriculture, food security and dietary intake. Agriculture is one of the most essential sectors in human development and it is related to food security (Abdelhedi and Zouari 2020; Kogo et al. 2020; Lopez-Ridaura et al. 2019). Studies have shown that an outbreak of any disease (for examples: Spanish Flu, Asian Flu, Hong Kong Flu, HIV/AIDS, SARS, Ebola, and Swine Flu) has always been accompanied with an increase in hunger and malnutrition (Burgui 2020) with a great impact on the economy, the environment and any human activity (Siche 2020). As such disease progresses, the situation worsens. The human "coronavirus disease 2019" (COVID-19) that originated in Wuhan, China in Dec 2019 and declared as 'a pandemic disease' by the World Health Organization (WHO) on March 11, 2020, is therefore not just a health crisis, but a social, economic and developmental issue affecting agriculture, food and nutrition security, requiring immediate and sustained actions. This disease spreads across the globe and cuts across every facet of human existence and its consequences are foreseen to linger beyond the year 2020. The pandemic has put the world on an emergency balance, with uncommon activities to confine developments and plans for radical distribution of private and public resources to battle the risk presented by a novel coronavirus that knows no limits (FAO 2020a). Prior to COVID-19 outbreak, the proportion of hungry and malnourished people across the globe was already on the rise due to such factors like an increase in violent conflict and climate change impacts with "more than 821 million people chronically undernourished between 2016 and 2018" (FAO, IFAD, UNICEF, WFP and WHO 2019), and over 100 million people in need of life-saving food assistance. COVID-19 outbreak is worsening the trend of insecurity of food, and likely to continue if urgent steps are not taken. Although the pandemic has presented opportunities to changes in food and agricultural systems (such as consumption of home-grown food, change in food distribution to the expansion of online grocery deliveries), the potential economic and food insecurity implications of COVID-19 when compared to the 2007-2008 financial crisis (which led to a food crisis) will be immense due to the lockdown of activities in many countries, which was not the case during the global financial crisis.

Specifically, the study (i) assesses the trend of COVID-19 in Nigeria between the end of February 2020 till the beginning of January 2021; (ii) examines the immediate short-term and potential long-term effects of COVID-19 outbreak on the socioeconomics, agricultural systems, security of food and dietary intake in Nigeria; (iii) assesses the various actions taken against the COVID-19 in Nigeria to prevent deteriorating socioeconomic, food security and dietary intake conditions of people in Nigeria; and (iv) suggests the potential mitigation strategies to combat the effects of COVID-19 on agriculture, food security and nutrition in Nigeria.

\section{Motivation of the Nigeria Case Study and Justification of the Study}

Nigeria is a West African country with an estimated population of over 200 million. The country's population growth rate has already overtaken food production rate with a wide food 
demand-supply gap. "Between 2016-2019, the country's cumulative agricultural import was A3.3 trillion, which is four times more than the country's exports of $\$ 803$ billion in the same period" (PWC 2020). Nigeria had an unemployment rate of $23.1 \%$ in 2018 with a projected rate of $33.5 \%$ by 2020 ; and underemployment rate of $16.6 \%$ (NBS 2019). The nation has also been identified as the poverty capital of the world with an estimated 87 million people living on less than $\$ 2$ a day threshold (World Data Lab 2019) (Fig. 1).

Like many other African countries, this study was undertaken using Nigeria case due to the nutrition situation prior to COVID-19 pandemic in which stunting and wasting rates were $37 \%$ and $7 \%$ respectively. Deficiencies in key micronutrients were also widely affecting the population, mainly children and women with only $34.5 \%$ children 6-23 months old meeting the minimum dietary diversity needed to ensure adequate intake of micronutrients such as vitamin A, iron, zinc and iodine (GON 2020) and less than half of the Nigerian children eat iron rich/fortified foods.

While various studies have examined potential impacts of the pandemic on global and national economic indicators such as global poverty, government expenditures, Gross Domestic Product (GDP) growth, budget deficits, employment (ILO 2020a; ILO 2020b; Nicola et al. 2020; Sumner et al. 2020; UN-Habitat and WFP 2020; World Bank 2020), there is limited information on how the pandemic and associated lockdown policies, affected individuals at the farm household level. Hence, understanding the farm household level impacts and supports mechanisms that can be harnessed to ensure income smoothing is important. Furthermore, given the high level of unpredictability in the trend of the COVID-19 infection's spread and the severity of the effects at the international level, a comprehensive analysis of the effect of the pandemic on socioeconomic characteristics, agriculture, dietary intake and food security is not yet available as far as we know probably due to the fact that the pandemic is still ongoing worldwide. Hence, it is important to understand the immediate socioeconomic consequences of COVID-19 and effects of COVID-19 on agriculture, food security and dietary intake while waiting for the long-term effects which involves the use of institutional data.

This study adds to the growing body of literature on the COVID-19 pandemic by examining the socioeconomic consequences of the COVID-19 outbreak and the induced lockdown restrictions in Nigeria as well as the implications on agriculture, food security and

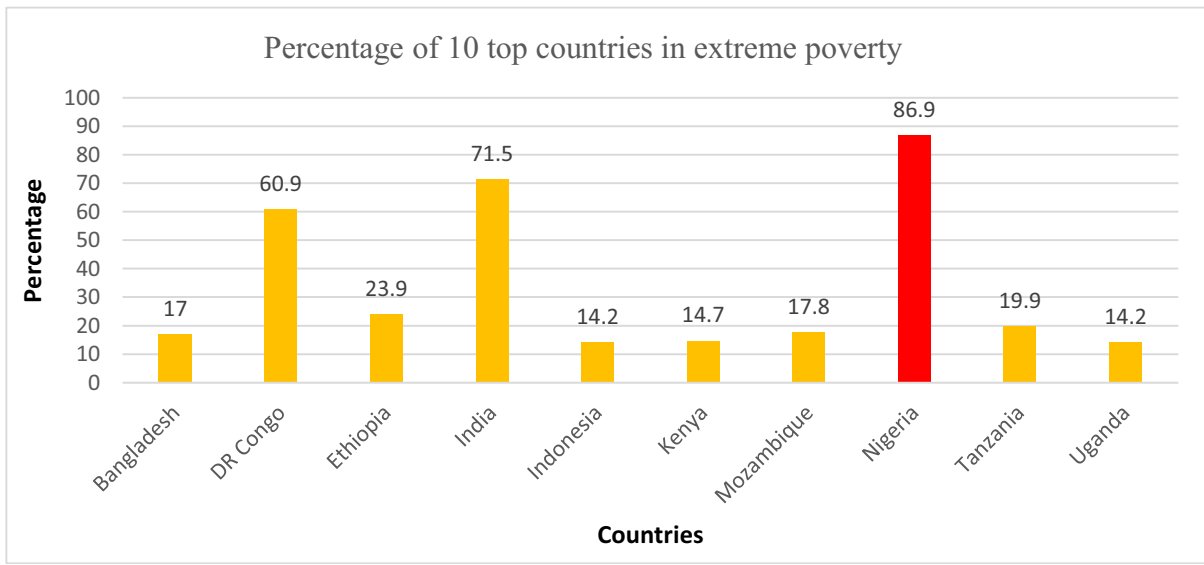

Fig. 1 People Living in Extreme Poverty in Nigeria relative to other countries as at 2018. Source: World Data Lab (2019) 
dietary intake by farm households. The results will contribute to understanding the critical needs of the farm households living in urban areas and control the negative consequences of the pandemic on their quality of life. The outcomes will also complement the existing knowledge to guide policy discussions on food security implications and coping measures during the COVID-19 pandemic and inform decision-making on preserving the livelihoods of households that are most vulnerable to the pandemic. The results would also chart a course of action on food ethics by governments, internal and international NGOs, health systems, and global organizations and designing responsive programs to meet the most urgent needs of farm households in Nigeria. It is against this background that this study embarks on a rapid assessment of the potential effects of this disease on the socioeconomic conditions, agriculture, food security, and dietary intake in Nigeria.

\section{Pattern of Spread of COVID-19 in Nigeria}

COVID-19 is an unprecedented challenge for Nigeria because of her large population and the economic dependence mainly on crude oil export. Nigeria recorded the first confirmed case of coronavirus (COVID-19) on the 27th of February 2020 by the Lagos State Ministry of Health, since the outbreak in China in January 2020. The pattern of an COVID-19 in Nigeria can be represented with a highly stylized s-shaped or logistic curve (Fig. 2). The prevalence of the pandemic was quite low at the initial stages followed by a period of acceleration where the virus is spreading at a rapid rate throughout the population. However, the situation is speedily growing with the curve of caseload moving upward (Fig. 2). The Nigeria Centre for Disease Control (NCDC) which is responsible to provide daily update of the level of COVID-19 in Nigeria had at the time of this study reported a cumulative number of 92,705 confirmed COVID-19 cases, 14,990 active cases, 76,396 discharged cases and 1319 deaths across all the entire 36 states and Abuja as at 5 January, 2021 (Figs. 2 and 3). Out of these, 1, 354 new cases

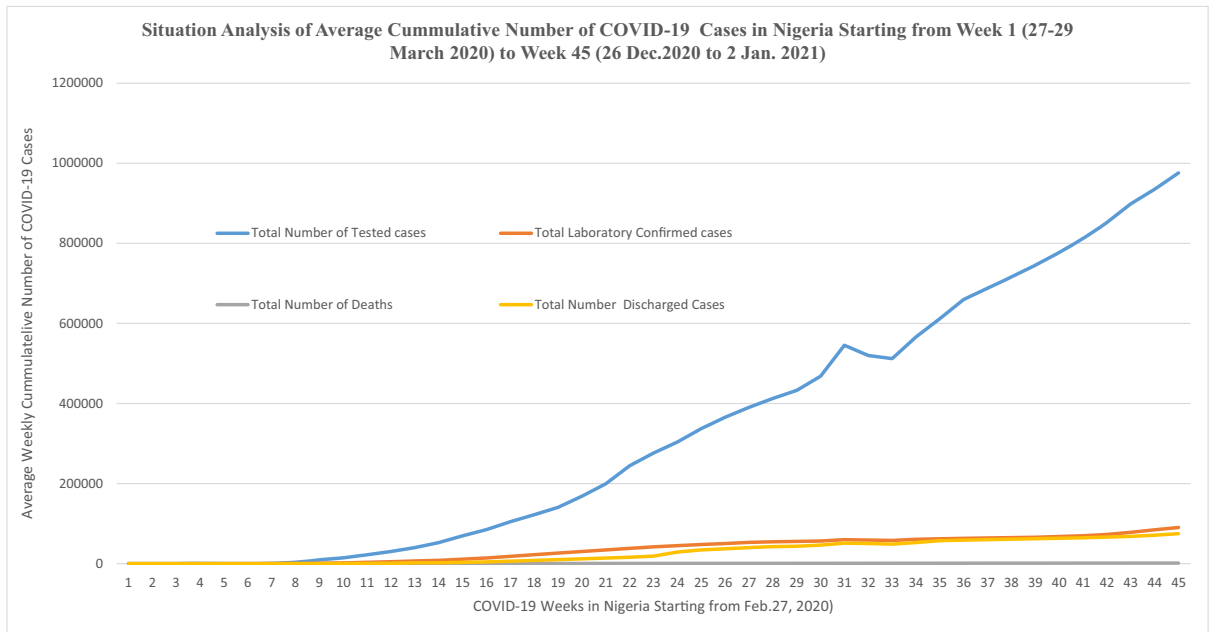

Fig. 2 Trends of average weekly COVID-19 pandemic situation in Nigeria starting from 27/2/2020 (week 1) to 02/01/2021(Week 45). Source: Data extracted from NCDC (2020) daily report on Nigeria COVID-19 from (i) http://covid19.ncdc.gov.ng/. (ii) https://ncdc.gov.ng/diseases/sitreps/?cat=14\&name=An\%20update $\% 20 \mathrm{of} \%$ 20COVID-19\%20outbreak\%20in\%20Nigeria 


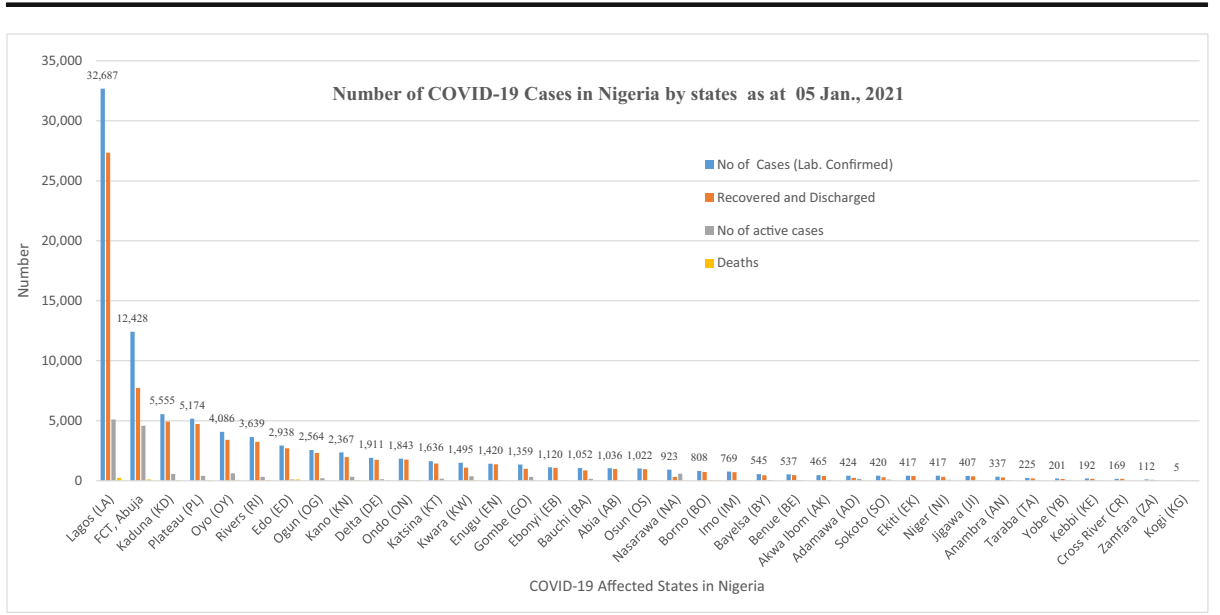

Fig. 3 Cumulative number of COVID-19 cases in Nigeria disaggregated by states as at 05 Jan., 2021. Source: Data extracted from NCDC (2020) daily report on Nigeria COVID-19 from (i) http://covid19.ncdc.gov.ng/. (ii) https://ncdc.gov.ng/diseases/sitreps/?cat=14\&name=An\%20update\%20of\%20COVID-19\%20outbreak\%20in\% 20Nigeria

(the highest daily figure since the outbreak of the virus) was reported from 21 states as at January 5, 2021 (NCDC 2021).

\section{Directions of Some Macroeconomic Indicators in Pre and Post COVID-19 Outbreak in Nigeria}

COVID-19 virus effects go beyond a shock on real economic fundamentals (such as interest rates, Gross Domestic Product (GDP) growth, inflation level) but a shock to the market that introduces 'a divider between demand and supply' with tough corresponding responses in the real economy. Reduction in food supply is leading to a reduction in demand and large destruction of economic surplus (Surico and Galeotti 2020). World food commodities prices such as vegetable oils, meat, cereal is reducing global food demand after COVID-19 outbreak compared to the pre-COVID-2019 period when people spent more on food (FAO 2020b). Inflation rate in Nigeria has maintained an upward trend during COVID-19. The rising inflation reduces consumer real purchasing power as it increased from $12.20 \%$ in February 2020 when Nigeria recorded the first COVID-19 case to roughly $14.89 \%$ in December 2020 (Fig. 4). Subsequently, the Consumer Price Index (CPI), which also measures changes in the prices paid by consumers for a basket of goods and services (National Bureau of Statistics (NBS) 2020), has also risen from pre-COVID period to COVID-19 period (Fig. 5). This is a pointer to the expected possible price increases in food due to the COVID-19 outbreak in Nigeria.

In addition, the annual average of $1.4 \%$ budgetary allocation to the Nigerian agricultural sector by the Federal Government over the past few years prior to COVID-19 outbreak is insufficient when compared to the growing population of about 200 million people of the country. Poor budgetary allocation to Nigeria's agriculture will make it difficult for the country during the post-COVID-19 to address issues relating to food and nutrition security mechanisation, insurance, research, and development among others that have continued to 


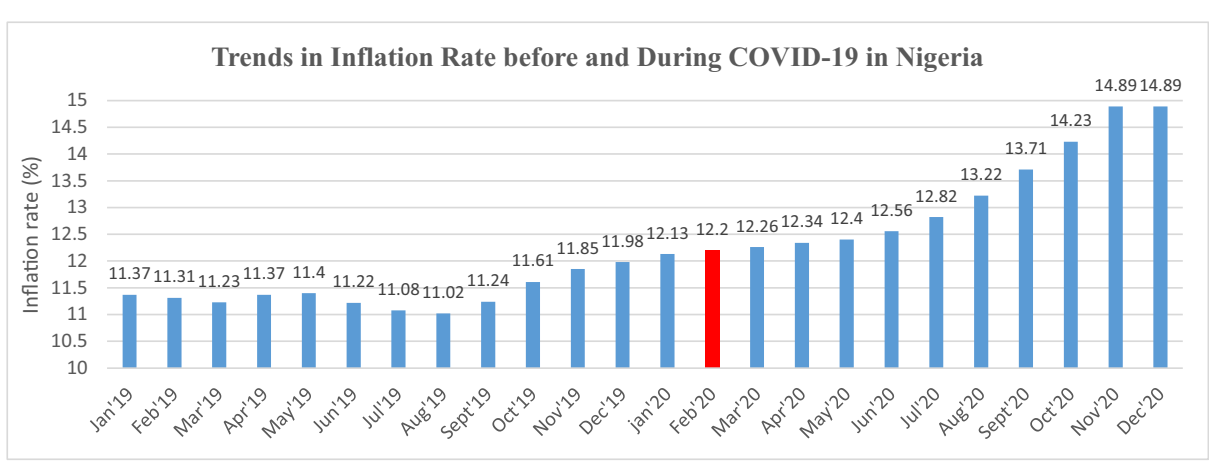

Fig. 4 Trend in inflation rate pre and post-COVID-19 in Nigeria. Source: Data from the National Bureau of Statistics, Nigeria (2020)

impact farmers' productivity negatively. Example of the low and dwindling allocation to agricultural sector responsible for food and nutrition security in Nigeria are drawn from the budgetary allocation to this sector (the percentage of the overall annual budget to all sectors), which increased from $1.25 \%$ in 2016 to $1.82 \%$ in 2017 and $2.23 \%$ in 2018 , but dropped in 2019 by $1.56 \%$ with a further decline by $1.3 \%$ of the overall appropriation in the 2020 budget prior to COVID-19 outbreak (Fig. 6). However, the revised budget allocation for agricultural sector fell by about $1.73 \%$ of the overall budget in 2020 due to a fall in the global oil price (which was used as a bench mark for the Nigeria budget) and triggered by the outbreak of COVID-19.

\section{Conceptual Framework on COVID-19 Outbreak, Socioeconomic Implications, Agriculture, Food Security and Dietary Intake}

Standard conceptual framework of food security is usually associated with four pillars: availability, access, utilisation, and stability (FAO 2008). Availability corresponds broadly to food supply. Access refers to effective demand for food (economic access) and proximity of markets (physical access). Utilisation is partly related to dietary quality while stability captures

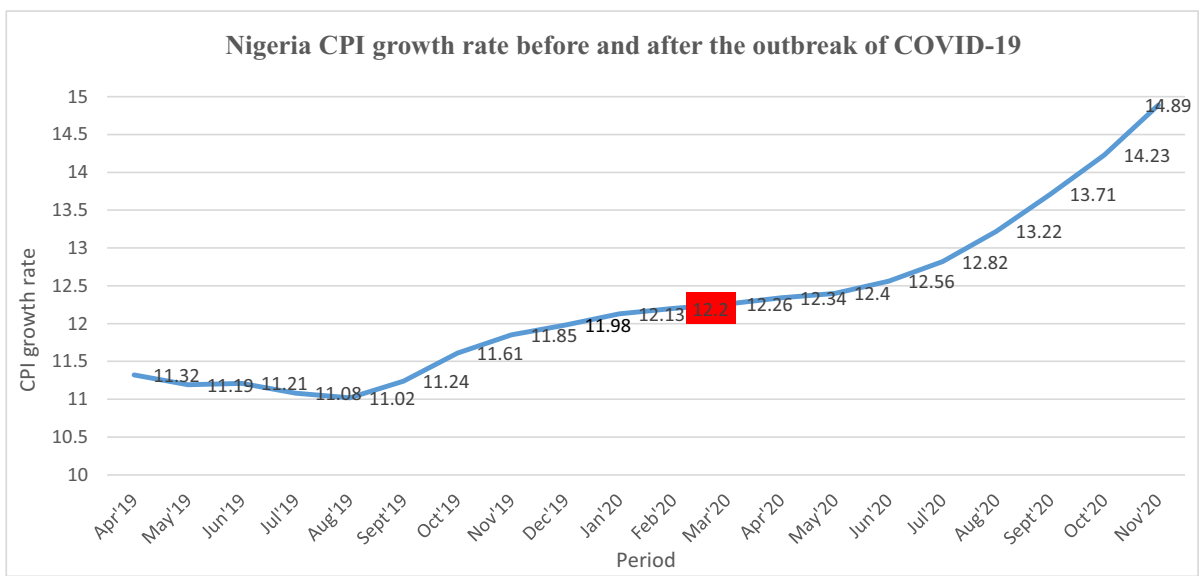

Fig. 5 Nigeria Consumer Price Index (CPI) from April 2019 to March 2020. Source: Data from NBS, (NBS 2020) 


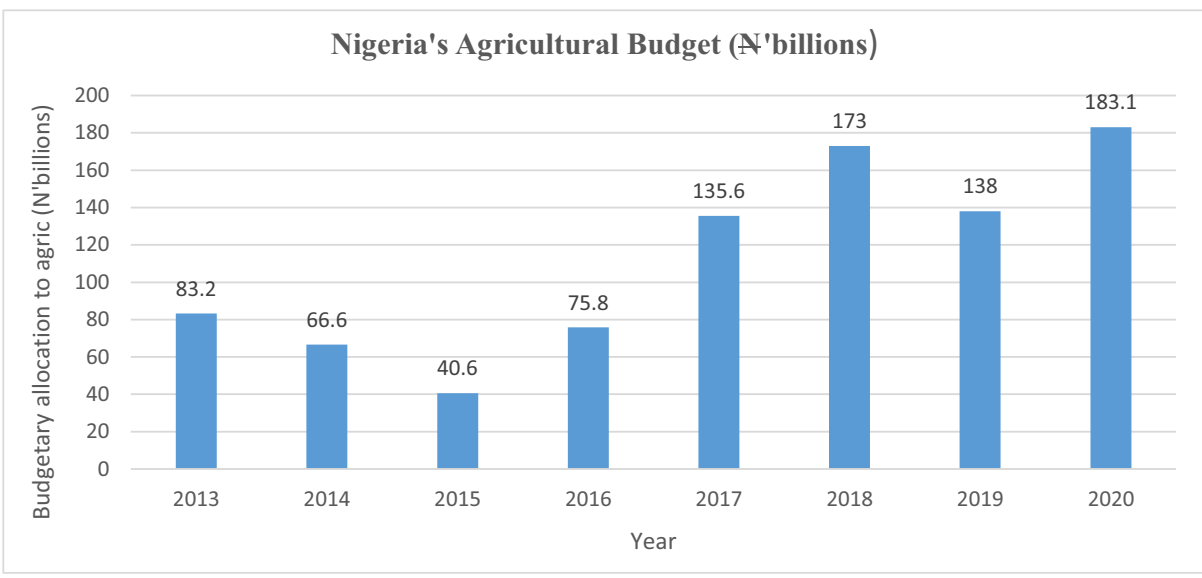

Fig. 6 Trend of the Budgetary allocation to agricultural sector in Nigeria. Source: Data from the Nigeria budget office of the federation (2013-2020)

the dynamic aspect since being food secure requires stability in the other three pillars over time. COVID-19 undermines food security both directly by disrupting food systems and indirectly through negative consequences of lockdowns on household incomes and physical access to food (Fig. 7). COVID-19 and responses to the pandemic could undermine food production, processing and marketing (Devereux et al. 2020). Food access is threatened by increases in food prices relative to wages or income. Stability of food availability and access is affected by COVID-19-related prohibitions on movement and the closure of informal food markets in order to achieve greater social distancing.

Based on literature review, COVID-19 pandemic has negative effects on socioeconomic status of households. Low socioeconomic status is highly related to household dietary intake and nutritional status. COVID-19 related restrictions affect all stages of the food supply chain,

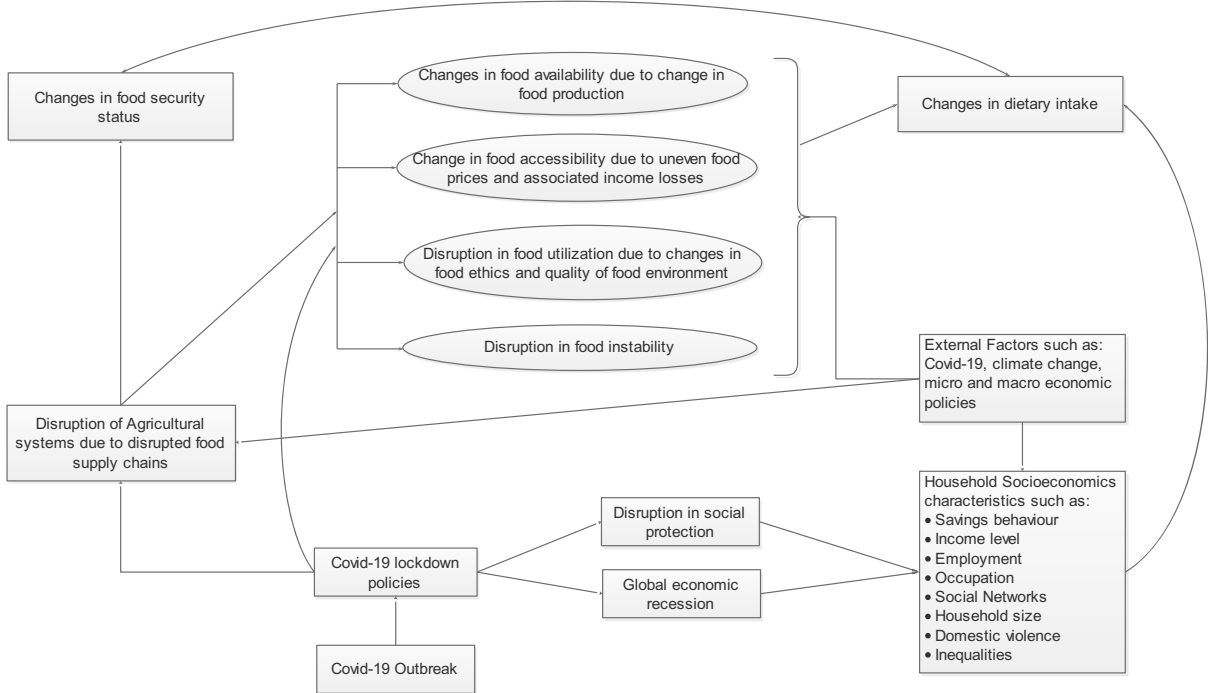

Fig. 7 Conceptual framework linking COVID-19 with households' socioeconomic characteristics, agriculture, food security and dietary intake. Source: Authors 
including production, distribution, processing, and consumption (Poudel et al. 2020; Siche 2020; Torero 2020; Nicola et al. 2020). Food production requires labour during the crop production cycle. Access to hired labour are also disrupted during COVID-19 outbreak either because prospective workers are unwilling to travel to work or due to prohibitions of movement mean or because strict enforcement of social distancing regulations restricts the number of workers who can work together. Likewise, food production requires the use of inputs such as seeds and fertilisers. Access to these is susceptible to disruptions in international shipping, closure of land border crossings, and in-country restrictions on mobility during COVID-19 lockdowns. A study using a system dynamics model suggested that a severe pandemic with $>25 \%$ reduction in labour availability can create widespread food shortages even in developed nations (Huff et al. 2015).

\section{Empirical Literature Review on COVID-19 Outbreak on Agriculture, Food and Nutrition Security}

The provision of food has always been a challenge facing mankind (Kansiime et al. 2020) even before COVID-19 pandemic. Few available studies (such as: Balana et al. 2020, Amare et al. 2020, Laborde et al. 2020, Swinnen and McDermott 2020, Schmidhuber et al. 2020, UN 2020, Torero 2020, FAO 2020c) have shown that COVID-2019 is negatively affecting agriculture through food supply and demand gap deficit, which is directly linked to food insecurity. Most current assessments generally predict a contraction in both supply of and demand for agricultural products as well as possible disruptions in trade and logistics in the long-run. The pandemic represents a unique shock that has a major impact on both the demand and supply of commodities (Commodity Markets Outlook 2020). While food and agricultural systems are exposed to both demand and supply side shocks (symmetric), these shocks are not expected to take place in parallel (asynchronous) since, among other things, consumers can draw on savings, food stocks and safety nets. Disruptions induced by the COVID-19 pandemic are threatening the food security of billions of people globally (Torero 2020; Zurayk 2020) and various analyses have pointed out that such global hunger could either be doubled or tripled due to food supply chain disruptions especially in poor nations across the globe. COVID-19 pandemic has been reported to influence food systems directly through effects on food supply and demand, and indirectly through reductions in buying power, the ability to produce and distribute food, and the heightening of care responsibilities (High-Level Panel of Experts (HLPE) 2020).

The border closures and domestic lockdowns in different countries have also led to unintended consequences through delays in delivery of produce to markets (Ivanov 2020), thereby causing substantial losses and increase in transport costs (AFAP 2020) and increase in prices of agricultural and non-agricultural commodities (FAO 2020a). Furthermore, COVID19 crisis has limited global agri-food trade and market access (Laborde 2020), limited seasonal and casual labor availability (Stephens et al. 2020) and constrained critical inputs like seed, fertilizer, plant protection products and on-farm equipment (Agrilinks 2020). The barriers to trade increase transaction costs, which in turn reduces margins for smallholder farmers and potentially decreasing their on-farm investments as well.

Using data collected from sample households from four Nigerian states, Balana et al. (2020) investigated the effects of COVID-19 pandemic policies on the incomes, employment, and food security situation of smallholder farming households in Nigeria. Their findings show that travel and movement restrictions from COVID-19 caused disruptions in agricultural activities and supply chains. 
Ceballos et al., (2020), Harris et al., (2020) studied the impacts of COVID-19 and related restrictions on smallholders in India and reported a large degree of heterogeneity in the impacts of COVID-19 responses on agricultural activity, income, and food security. Matsungo and Chopera (2020) also examined the effect of the COVID-19-induced lockdown on nutrition, health and lifestyle patterns among adults in Zimbabwe and reported that the lockdown period was associated with increase in food prices, decrease in dietary diversification, disrupted diet and consumption patterns.

Moreover, Welsh (2020) explains that the pandemic is affecting food systems directly by distorting supply and demand internationally; and indirectly by degrading the purchasing power of the population and by undermining the capacity to produce and distribute food. Devereux et al. (2020), Bakalis et al. (2020), Farrell et al. (2020) also emphasize the two-faced nature of direct (disrupted food systems) and indirect (undermined economic access to food) effects of COVID-19 on food security. According to Sidor and Rzymski (2020), home confinement is associated with unhealthy dietary patterns such increased in frequencies of eating unhealthy food, eating out of control, snacking between meals, and having an increased number of meals per day.

\section{Materials and Methods}

The assessment of the immediate and long-term effects of COVID-19 outbreak on the economic, agriculture, security of food, and dietary intake is extremely difficult due to the limited data currently available. The considerations in this study are thus mainly based on personal observations, public opinion through mobile telephone survey of farm households residing in Lagos and Ibadan in Lagos and Oyo States, Nigeria, respectively, but have their farms located outsides their places of residence. The study was undertaken between May and June, 2020 to harvest their perceptions and implications of COVID-19 outbreak on the economy, agriculture, availability and access to food, and dietary intake.

Mobile telephone survey is a quantitative research method use to collect information about what people think and how they behave. This method of interview has been used to collect qualitative data to inform or explain more traditional survey results (Cooper and Kurland 2002; Malhotra et al. 2005; Martins 2005). Telephones have been used to access populations that might be difficult to reach in person or by other means (Ilies et al. 2007; Maritan 2001; Sturges and Hanrahan 2004). Telephones give researchers access to varied resources and experiences without the need to endure the expense and time consumed by travel to different locations. Telephone interviews is also an easy way to gather contextual information for quantitative studies because it takes lesser time than face-to-face interviews (Sobo et al. 2003). For instance, the rapid phone surveys were done with Rapid Response Phone Surveys (RRPS) by the World Bank in a number of countries (Delius et al. 2020). Mobile phone survey was conducted by the World Bank during the Ebola crisis in Liberia and Sierra Leone in 2015 to measure the socioeconomic impact of Ebola on households using samples of the previously interviewed in the household income and expenditure surveys and labor force surveys. The Nigerian COVID-19 National Longitudinal Phone Survey (NLPS) in 2020 was also conducted using sampled households interviewed in 2018/2019 for Wave 4 of the General Household Survey- Panel (GHS-Panel) to measure the impact of the pandemic on employment and livelihoods, food security and access, and human development are good examples. 
This study was a rapid assessment survey that comprised of a structured questionnaire package (See Appendix 1) that inquired socioeconomic and demographic information (age, household size, marital status, gender, occupation), components of food security (availability, access utilization and stability of foods) and dietary habits information (types of diet, daily intake of certain foods, food frequency, and number of meals/day). Dietary intake implications of the COVID-19 crisis were explored by asking the respondents to indicate how often they consumed different food groups before the COVID-19 pandemic and during the COVID-19 period. We used a mobile telephone interview method based on travel restrictions and COVID-19 lockdowns in Nigeria. We first obtained the list of telephone numbers of farmers who reside in Lagos and Ibadan but have their farm(s) located outside the place of residence from the contacts list of Lagos State ADP and Oyo State Agricultural Development Programme (ADP), respectively. In the second phase, farmers with active telephone contacts were approached through calls to seek their consent to be interviewed on how they felt during the COVID-19 outbreak and lockdown in Nigeria with respect to their socioeconomic status, agricultural production and their dietary intake. Those who were readily available were then interviewed at their own convenient times. The total number of people approached for the interviews were 103 through a snowballing method. Seventy-two farmers consented and participated in the interview (34 in Lagos and 38 in Ibadan) while the rest refused mainly because they were unhappy with the government's COVID restriction policies, which made things so difficult for them. The average duration of the survey was $13 \mathrm{~min}$.

\section{Results and Discussion}

\section{Socioeconomic Characteristics}

The results of the socioeconomic and demographic composition of the respondents interviewed in the study presented in Table 1 showed that majority were male practicing agriculture as their primary occupation with mean age and household size of 51.5 years and 3 members, respectively. The main source of income for almost all the respondents was agriculture. Most (77.8\%) had primary education and stop saving their money in banks during

Table 1 Characteristics of survey respondents

\begin{tabular}{lll}
\hline Characteristic & Definition & Respondents $(N=72)$ \\
\hline $\begin{array}{l}\text { Mean age (range) - yr } \\
\text { Household size (range) - no }\end{array}$ & & $51.5 \pm 15.6(19$ to 72$)$ \\
Gender - no. (\%) & Male & $3.1 \pm 1.6(1$ to 12) \\
& Female & $47(65.3)$ \\
Marital status - no. (\%) & Married & $26(36.1)$ \\
& Single & $65(90.3)$ \\
Occupation - no. $(\%)$ & Agriculture as primary occupation & $08(11.1)$ \\
Main source of income -no. (\%) & Agriculture & $68(94.4)$ \\
Level of education & Completed primary school (6 years) & $68(94.4)$ \\
Saving behavior - no. $(\%)$ & Stop saving & $56(77.8)$ \\
\hline
\end{tabular}

Note: Plus-minus values represent \pm Standard deviation

Source: Data from the field survey, 2020 
the COVID-19 (93.1\%) due to restrictions of movement (95\%), stress customers undergo for COVID-19 protocols in banks (100\%) and contingencies at home $(90.1 \%)$.

\section{General Background Issues Affecting the Socioeconomic Implications of COVID-19 Outbreak in Nigeria}

Not knowing how this COVID-19 pandemic will play out affects both the social and economic sectors. Financial markets and vulnerable industries such as manufacturing, tourism, and travel have been affected. There are warnings by the Nigerian security agents to members of the public to be sensitive to the increasing number of criminal activities of internet fraudsters. The criminals were using COVID-19 outbreak and government lockdown order to generate and spread mischievous websites, and chopping tools to access business data from people's laptops, which were no longer secure outside the business office environment. Social distancing and lockdowns likewise incited selfless practices with people seen donating food and materials in their communities, local government, and state to the less privileged (the vulnerable). About $90 \%$ of the respondents complained of being exhausted or worried about gaining weight; while $98 \%$ reported a slower pace of life due to their inability to go out but this also gave them more time for their families. Our finding shows that the closure of educational institutions including the children day-care following COVID-19 outbreak in Nigeria to fight against its spread created additional burdens on working parents. There was also a colossal measure of deluding data flowing on the web about COVID-19, from counterfeit clinical data to theories about government reactions. Families spent extra time at home due to the lockdown which resulted in increasing social and economic insecurities arising from increasing tensions in the households. Consequently, domestic violence and sexual abuse increases during lockdowns. Meanwhile, young women are subject to increased cyber-violence as people spend more time at home and online as quarantines and self-isolation measures continue (Ekweonu 2020; Oguntayo et al. 2020; Ilesanmi et al. 2020). Remittances from abroad, which support households, may also fall and worsen economic hardship. Around $\$ 25$ billion of remittances (equivalent to the Federal Government of Nigeria budget) came into the country in 2019 (Bakare and Fatai 2020).

We observed that individuals who are self-segregating (the aged, pregnant women with underlying health conditions) were scared of the disease and stayed at home for the fear of being infected (although it was still very difficult to identify the number in this category) thereby affecting the quantity of food sold by the marketers.

On households' income and expenditure, Nigeria is still a country where it is hard for people to feed themselves as most people live on less than $\$ 2$ a day. Isolation of people as a result of COVID-19 has positive externalities on health as most people have taken to some health precautions like regular hygiene. It has also created negative externalities on the economy. Confining members of the public to their homes could pose health risks for many low-income individuals and families (McKibbin 2020). The inability of the non-salary earners to do paid work from home is affecting the daily income earned. The effects of reduced income may include inability to pay children's school fees, pay rent and consequently eviction in the medium or in the long term.

Restriction of movements and road closures have resulted in the accumulation of fresh produce, food, and losses, while those who grow it lose income. Consumers could not spend much money during lockdowns because of self-isolation, firms cutting down the costs of production and reduction in the number of workers going to work due to the partial lockdown 
in most states in Nigeria. Consumers with large disposable income stocked up food, water, and medicine while those with low disposable income suffered. Income losses are anticipated to outstrip $\$ 220$ billion in the developing nations. With an estimated $55 \%$ of the worldwide population having no access to social protection, these losses will resound across societies promoting extreme negative effect on food security and quality of diet (UNDP 2020). Consequently, low salary earners, who need extra cash to feed youngsters whose schools were shut and whose instructive accomplishment and social improvement were hampered for an unknown length of time, found it difficult to decide on either buying food, utilities, and other necessities with the little money they had on them.

Below are some of the excerpts from the interview about respondents' behaviour on spending during COVID-19 lockdown in Nigeria:

"We eat more and spend more on food since all our family members are at home due to COVID-19 lockdown order by the government" - Interview numbers 1,3, 5, 10, 17, 21, $33,52,63$

"Apart from food, we spend less on non-essential commodities since we do not know what will happen next whether the lockdown by the government will continue. We spend less to (i) have enough money to buy food and (ii) wait for the prices of commodities which are higher now due to COVID-19 outbreak to fall after the outbreak lockdown order is lifted." - Interview numbers 4,5, 10, 19, 32, 48, 60, 70

\section{Implications of COVID-19 on Agriculture, Households and National Food Security}

Most, if not all, agricultural activities in Nigeria are season-specific, weather-dependent and follow a fine-tuned timing. A delay in one activity such as land preparation, seeds supply, feeds, fertilizers, pesticides, required in production process affects yields and output. Maintaining a functioning input system in agriculture is therefore critical for a smooth functioning of the food supply chain (from "farm to fork"). A household is only food secure if everyone has unrestricted access to food that allows them to satisfy their basic needs (Rosales and Mercado 2020).

The restrictions of movement impeded farmers from cultivating and food processors who handle most of the rural farm products (Balana et al. 2020). The deficiency of fertilizers, veterinary medicines and other information could negatively impair agricultural production. Lockdown of eateries and less successive shopping for food decrease consumers' interest in new product with negative ripple effects on production, processing and distribution systems. Although the movement restrictions exempted people who were into the production and sale of food, the purchase of inputs and sale of products was observed to have dwindled in Nigeria. The planting time by farmers was likely delayed in the year 2020 due to a reduction in the availability of labor at the time of the outbreak of COVID-19 being the peak seasonal times of land preparation and planting. Agricultural production in 2021 is likely going to suffer from a high probability of having an internal food demand crisis as food demand may not likely going to be met, and stress on agricultural imports may upsurge with implications of the increase in food prices similar to what happened in 2008 due to financial crisis. Interruption of farmer's cropping timetables will probably build water demand for irrigation and in certain areas, strengthen dangers and pressures related to water shortage (CGIAR 2020). Covid-19 has caused a devastating labor shortage in terms of a decrease in the labour supply by the number 
of individuals who bite the dust; the hours lost because of infection; and the hours lost because of individuals thinking about relatives who are sick (Amare et al. 2020). Although decreases in industrial and transportation actions due to lockdown help at diminishing discharges for the time being, the pandemic indirectly affects the battle against climate change. Resources conserved from mitigating against climate change can therefore be diverted to agriculture and health.

Furthermore, Social restrictions/lockdown approach, which is one of the measures used by the Nigerian government to prevent the spread of COVID-19, makes it difficult for some people to purchase and access food (constrained access to an adequate amount of reasonable food). Although those into agriculture were exempted from movement restriction, the fear of been infected did not allow the aggregators to purchase at the farm gate. This leads to income reduction for farmers. Reduced incomes limits farmers' ability to hire farm labor which is highly restricted as a result of COVID-19 as people avoid collective work in fields.

The effects of restriction measures are already being felt in Nigeria with small businesses and market traders been hit hard. The following are some of the excerpts from the interview:

"The restriction in the movement has disrupted supply. I have a difficult time getting my produce to the market. l had to bribe security agents and that is making prices to rise even though in theory, the government announced that all supply and distribution of food are exempted from restrictions but this is still very hard to enforce properly by our security agencies" (Interview number 3). These were corroborated by respondents 6, 7 , 12, 27,33,51, 62-68, 72 .

"I relocated to Lagos in search of safety, hoping for a chance to rebuild my life. Instead, the virus is putting my life and livelihood at risk with difficulty in getting what to eat due to Coronavirus lockdown"(Interview number 4). This view was supported by responses from respondents $7,11,18,25,46,57,60$.

"Since I have no vehicle on my own and my fish farm is located outside, the travel restrictions have prevented me from feeding my stock properly and blocked customers from picking up their orders. My profits have been wiped off and losses are piling up. Feed prices and transportation costs have gone up" (Interview number 5). These views were similar to the ones from respondents 17, 19, 37, 46, 62, 71.

"Every aspect of the poultry value chain has greatly been affected by the lockdown. I am unable to supervise activities on the farm since I do not live on the farm. The movement of the input supply is affected because of the interstate travel ban. Fewer supply comes with an increased rate because of the difficulty in movements, which has negatively affected our budget. The consumer has to buy at an exorbitant price because we have not only bought at an increased rate but have also risked our lives during operations" (Interview numbers 6). These views were further buttressed by respondents 32, 40, 63.

\section{Potential Effects of COVID-19 on Dietary Intake}

Food is often one of the immediate causalities of any catastrophe in Nigeria and the country is not winning the war against acute hunger and malnutrition as millions of Nigerians are still food insecure and malnourished. Nigeria still heavily relies on some imported food to meet demand and is facing disproportionate risk from supply chain failures, especially in the face of 
border-crossing closures. The lockdown poses extreme challenges for many families who could not procure food supplies and panic buying. Blockages to ship are especially obstructive for new food supply anchors and have brought about high degrees of food loss and waste. Transport limitations and isolate measures were found to have obstructed farmers' entrance to business sectors, controlled their beneficial limits and prevented them from selling their produce. Limitations to movement have not just diminished the utilization of insignificant wares in general, they have also influenced the income-generating ability of the people and cut their consumption expenses.

The emergence of COVID-19 has presently, in a general sense, changed individuals' lives concerning general wellbeing as well as governmental issues, the economy, open administrations, and a lot more. One thing that cannot be put on hold is people's need to feed themselves. We find that people in urban areas found it difficult to get food under COVID-19. COVID-19 outbreak has an attendant effect on access to adequate, diverse and nutritious foods. Furthermore, over 9,300,892 students benefitting from the school food feeding program missed a major opportunity from school meals because of school closures caused by COVID-19 outbreak (Today Nigeria Newspaper 2020). A significant number of these youngsters are from poor families who rely upon the day by day meals they get at school. The effects of COVID-19 on these children and their families are terrible. A majority of these youngsters are in danger of hunger and are no longer having the security of key nutrients and micronutrients they get in the school meals, being the only nutritious meal during the day (The United Nations World Food Programme 2020). For these poor families, the estimation of a meal in school is identical to around $10 \%$ of a family's month to month pay. For families with a few youngsters in school, that means significant reserve funds to them. The loss of school meal is like a reduction in income beyond the effect on the nutritional status of their children. The effect of the COVID-19 outbreak on women who are responsible to take care of children, the sick, and the elderly in the household also affects food preparation and household dietary intake.

Moreover, a COVID-19 impact survey conducted by the National Bureau of Statistics (NBS) shows that a $51 \%$ of households reduced their food consumption to cope with the shocks of the pandemic (NBS 2020). Findings have also shown that many people are willing to spend a larger share of their income on foods, but most poor households cannot afford this. Therefore, inequality in food consumption is likely to increase. About $65 \%$ households interviewed was found to rationed food they eat, while some skip meals or go for low-cost food due to low income caused by lockdown ordered by the government to prevent the spread of the disease in the country. This was in agreement with Balana et al. (2020) who reported a significant reduction of consumption of proteins (eggs, meat, and dairy products) and fruits among smallholder farming households in Nigeria due to COVID-19 outbreak.

The followings are some of the excerpts from the interview to corroborate the effect of this disease on household dietary intake in the study area:

"I have to cut down the quantity and quality of food we consume in my household because of lack of money and the fear that the food will run out before we can get money for another one before COVID-19 lockdown is lifted" (Interview number 1). This response was similar to responses of respondents 4-9, 37, 65. 68.

"My household can no longer spend what we used to spend on food during the COVID19 lockdown. We have to replace some of the foods we use to eat such as food and vegetables with less nutritious ones like cassava products which are cheaper since we are not sure when COVID lockdown will be over. We have to do that in order to take 
care of other things such as buying medicines for our health, save for the children resumption to school which may be anytime" (Interview number 2). Similar views were also expressed by respondents 9, 13,40, 62, 71.

"Owing to the fear of being infected with COVID-19, I have stopped eating away from home to reduce contact with other people; lower the chance of being exposed to the disease; and be able to maintain the recommended social distance of at least 1 meter between myself and anyone that may be coughing or sneezing, which may be impossible to do at restaurants and cafes" (Interview 10). Similar responses were also expressed by respondents 29, 34, 51, 63 .

\section{Nigerian Government Actions and Mitigating Strategies against COVID-19 and Sustainable Food Production and people's Perceptions}

Since the outbreak of COVID-19, Nigeria has tightened its borders, restricted gatherings, closure of schools besides the common protective measures against being infected by COVID19. The Nigeria government initiated the Presidential Task Force on COVID-19 with the Nigeria Centre for Disease Control (NCDC) to provide updates on the disease at the press briefing convened daily by the Office of the Secretary to the Government of the Federation. The Federal Government directed the cessation of all movements in Lagos, Abuja, and Ogun for an "initial period" of 14 days from March 30, 2020, and further extension by another 14 days starting from April 14, 2020, to stop Coronavirus in Nigeria. Virtually all the state governments in Nigeria have closed all interstate routes.

The Nigerian government has also put a safety net system (such as the extension of the terms for payment of loans, provision of one-time conditional cash transfers) in place to weaken the effect of the COVID-19 on the most vulnerable portions in the locked-down states and the Federal Capital Territory (Lagos, Ogun, and Abuja). However, this economic assistance has exposed inadequacies of Nigeria's social protection systems and risks excluding the country's poorest and most vulnerable people. This is based on numerous criticisms, which the Federal Government has been getting on the structure, transparency, efficiency, and mode of operation of the Government's social investment program of which the conditional cash transfer is a critical component. Some of the excerpts from the interview are shown below:

"I have never been impressed for one day by how they've identified the poorest of the poor and the impact. The bulk of the money did not get to its intended beneficiaries" (Interview number 7). Respondents 9-15, 20, 30, 43, 55, 60, 70, also gave similar view.

"The government is suspected to have deliberately acted in this manner to blur the line of accountability, disguising the conditional cash transfer as payment under the COVID-19 intervention and relief package" - Interview numbers 6. 13-16, 30, 47, 59, 65,72 .

"The Federal Government of Nigeria is confusing us with the Conditional Cash Transfer program launched in 2016 with the palliative measures aimed at reducing the economic hardship associated with the COVID-19 spread and governments' lockdown directive. The two are not the same" - Interview numbers 7, 11, 17, 20,4365. 
"The cash transfer provided for the 'poorest of the poor' by the Federal Government was lopsided. About twelve percent of the cash had gone to the entire South, while eightyeight percent remained in the North."- Interview numbers 8, 9, 13, 20, 23, 51, 69.

As parts of policy response of the Nigeria government, the Central Bank of Nigeria (CBN) masterminded a financial improvement bundle, including a $₫ 50$ billion ( $\$ 138.89$ million) credit facility to family units, small and medium ventures generally influenced

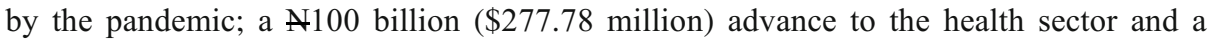
trillion naira ( $\$ 2.78$ billion) to the manufacturing sector. Also, the interest rates on all $\mathrm{CBN}$ interventions have been revised downwards from 9 to $5 \%$, and a one-year moratorium on CBN intervention facilities has been introduced, effective from March 1, 2020 (CBN 2020). Likewise, the financing costs on all CBN intercessions have been overhauled downwards from 9 to $5 \%$, and a one-year ban on CBN mediation facilities has been initiated starting from March 1, 2020.

Governments and development partners will need to bridge administrative silos across national and sub-national ministries/agencies for effective outreach on scale to rural areas; introduce basic good agricultural practices; and investments to allow farmers to buy seeds, educate them on pests' management, irrigation and on plant growth principles. This is due to loss of knowledge by many farmers as a result of old age and loss due to older people dying from the pandemic.

\section{Conclusions and Recommendations}

There are some evidences to affirm that COVID-19 pandemic has important effects on agriculture through disruption in food supply chain and lost in the numbers of days incapacitated by the affected farmers to work on the farm. Supply chain disruptions by COVID-19 influence the shapes of both demand and supply, while monetary hardship influences the total quantity of food that can be purchased and choices of the supply chain and ultimately affects food security and nutrition outcomes. The COVID-19 pandemic interrupted the supply chain especially food production, food accessibility, and food utilization. It also leads to a widespread income loss, apportioning of food and other fundamental merchandise, disturbances to social insurance administrations and training, and a decrease in food intake among children of poor families who depend on school feeding programs.

Restrictions of movements and road closures resulted in the accumulation of fresh produce not sold, leading to market gluts, food losses, and a drop in income of the farmers. A global recession may likely be unavoidable, which is anticipated to escalate hunger, and reduce global struggles in attaining Sustainable Development Goal 2 targets.

The downward pressure on prices of foods would likely support higher consumption of cereals and roots and tubers and diminish the supply operations for fruits and vegetable and intakes of these foods. The outcome would not necessarily be an increase in undernourishment, but expansion of the double/triple burden of malnutrition with more overweight and obesity, as well an increase in micronutrient deficiencies. A reduction in income is likely to result in reduced access to foods. Since nutritious, fresh foods are often more expensive than nonperishable staples, it is expected that the price of nutritious foods will rise faster and become less accessible for the more vulnerable segments of the society. 
The study therefore recommends the following:

(i) There is the need to introduce basic good agricultural practices and investments to allow farmers buy seeds; educate them on pests' management and irrigation; and on plant growth principles due to death of older people from the pandemic.

(ii) There is also the need to put in place logistics (including storage, transport, and protective gear) to move food from places of production and surplus to places of deficiency.

(iii) Nigeria needs to reinforce her social protection programs for the most defenseless (older, incapacitated, pregnant women, babies, school children who rely on school feeding programs, detainees and different gatherings that are reliant on taking feeding programs).

(iv) Although the government has correctly issued lockdown guidelines that exempt farm operations and supply chains, the implementation problems leading to labor shortages and falling prices should be rectified.

(v) Governments at all levels need to develop and work together around food security and farming arrangements. This will lead to the option of diminishing the dangers of food ban and consequently guarantee access to food by the populace.

(vi) Any viable reaction to a COVID-19-related food emergency requires a rebuilding of the national food framework. Like clinical considerations, food must be permitted to cross outskirts unreservedly. Producers of food must guarantee that sound, nutritious food sources are accessible and not squandered.

(vii) Farmers and agricultural workers should be included in the governments' assistance package and social protection programs used to address the crisis. Individuals should plan their food expenditure wisely and share with their neighbors.

(viii) Creation of strong demand for and access to agricultural inputs through smart input subsidies and promotion of measures for prevention of food price hikes are necessary measures. For instance, the governments at all levels can release food from government grain reserves and implement an anti-hoarding policy.

(ix) Sound food security and agricultural policies are vital to mitigate the outbreak and the shocks on food supply chains. Access to accurate information that helps people plan for and react to changing situations is also necessary for people to make the best decisions, given their circumstances.

(x) Government can ease the danger of food deficiencies and significant expenses by giving boost bundles that will balance out the rural part with seed dispersion, fertilizer projects and subsidies for tractors and other apparatus needed in farming.

(xi) Government can increase its focus on nutrition besides food security and raise farmers' income rather than enhancing farm productivity alone.

\section{Limitations and Suggestions for Further Studies}

Data used in this study was based on a rapid mobile phone survey, as COVID-19-induced social distancing and lockdowns did not allow face-to-face interviews at the time of the data collection. The data was limited by its convenience sample, moderate sample sizes across two cities in two states in Nigeria and the amount of information. These limited the generalisation of our findings. However, the data provided useful information for exploring some of the immediate implications of the COVID-19 crisis, which future research involving 
representative and longitudinal samples or alternative survey methods can build upon and extend. We suggest the followings for future research:

i) Trade impacts of COVID-19 pandemic on the distribution of food in Nigeria

ii) COVID-19 effects on food loss and food waste in Nigeria

iii) Effects of COVID-19 on hidden hunger by households in Nigeria

iv) COVID-19 effects on children nutrition in Nigeria

v) Effects of COVID-19 on households saving behavior and consumption patterns in Nigeria

vi) Impact of COVID-19 on sustainable healthy diets in Nigeria

vii) Effect of COVID-19 on food price volatility in Nigeria.

\section{Useful Links for the Nigeria COVID-19 Data Update}

For further updates on the daily trajectory number of confirmed laboratory cases, active cases, death and recovery rate of COVID-19 visit:

(i) https://www.worldometers.info/coronavirus/?utm_campaign=homeAdvegas 1? This give the daily update of the spread, number of cases and death rate of COVID-19 by country and region

(ii) http://covid19.ncdc.gov.ng/

(iii) (iii)https://ncdc.gov.ng/diseases/sitreps/?cat=14\&name=An\%20update $\% 20 \mathrm{of} \%$ 20COVID-19\%20outbreak\%20in\%20Nigeria

(iv) https://en.wikipedia.org/wiki/2020_coronavirus_pandemic_in_Nigeria .These sites give the daily update of the number of cases, death and recovery rate from COVID-19 in Nigeria

\section{Appendix}

\section{Interview Guides}

Based on COVID-19 outbreak and subsequent lockdowns (partial or total), this study attempts to assess the socioeconomic consequences of COVID-19's and the effects on agriculture, food security and dietary intake with sample respondents from Lagos in Lagos State and Ibadan in Oyo State.

This interview protocol elicits information/data from you and the information/ data obtained through this this interview would strictly be kept confidential and use only for this research purpose. Your participation in answering these questions is very much appreciated.

\section{Consent}

Before I start, do you have any questions or is there anything which I have said on which you would like any further clarification? May I proceed with interviewing you?

Yes $\square$ No $\square$.

If answer is no, please state the reason for refusal. 


\section{Questions}

1. Kindly briefly speak about your demographic and socioeconomic characteristics of yourself/ household in terms of your gender, age, marital status, education level, occupation (main and secondary), source(s) and level of income, saving behavior, household size, membership of social groups and level of physical contacts during COVID-19 lockdown

2. How is the COVID-19 pandemic affecting (i) food production, (ii) food demand and (iii) food prices?

3. Has your lifestyles and eating habits of your household changed during the COVID-19 pandemic period?

4. Kindly tell us about your household saving behaviour during COVID-19 lockdown?

5. During this period of COVID-19 induced lockdown, which of the foods are you consuming (i) more, (ii) less than before COVID-19?

6. What are the prevalence food situation challenges in your household during COVID-19?

7. What is your level of concern for food access among members of your households and current coping strategies to increase food access during this period of COVID-19 lockdown?

8. What do you think are the lessons learnt from the COVID-19 pandemic on agricultural systems, households' socioeconomic lifestyles, and dietary intake in Nigeria?

9. State the dietary strategies adopted to cope with the effects of COVID-19

\section{References}

Abdelhedi, I.T., and S.Z. Zouari. 2020. Agriculture and food security in North Africa: A theoretical and empirical approach. Journal of the Knowledge Economy 11: 193-210. https://doi.org/10.1007/s13132-018-0528-y.

AFAP. 2020. COVID-19 impact-effects on livelihoods in Burkina Faso. Africa fertilizer and agribusiness partnership, Johannesburg, South Africa.

Agrilinks. 2020. COVID-19 and the new risks for global food security and nutrition. Feed the future enabling environment for food security (EEFS) Available online at https:/www.agrilinks.org/post/covid-19-and-newrisks-global-food-security-and-nutrition Accessed on 16 July 2020.

Amare, M., K.A. Abay, L. Tiberti, and J. Chamberlin. 2020. Impacts of COVID-19 on food security: Panel data evidence from Nigeria. IFPRI discussion paper 1956. Washington: International Food Policy Research Institute (IFPRI). https://doi.org/10.2499/p15738coll2.133866.

Bakalis, S., V. Valdramidis, D. Argyropoulos, L. Ahrne, J. Chen, P. Cullen, E. Cummins, A.K. Datta, C. Emmanouilidis, T. Foster, P.J. Fryer, O. Gouseti, A. Hospido, K. Knoerzer, A. LeBail, A.G. Marangoni, P. Rao, O.K. Schlüter, P. Taoukis, E. Xanthakis, and J.F.M. Van Impe. 2020. Perspectives from CO+RE: How COVID-19 changed our food systems and food security paradigms. Curr Res Food Sci 3: 166-172. https:// doi.org/10.1016/j.crfs.2020.05.003.

Bakare, A., and R. Fatai. 2020. Four (4) ways the Nigerian government could minimize the impact of COVID-19 Available at https://www.one.org/africa/blog/how-nigeria-minimize-impact-covid-19/ Accessed 14 Aug 2020.

Balana, B.B., M.A. Oyeyemi, A.I. Ogunniyi, A. Fasoranti, H. Edeh, J. Aiki, and K.S. Andam. 2020. The effects of COVID-19 policies on livelihoods and food security of smallholder farm households in Nigeria: Descriptive results from a phone survey. IFPRI discussion paper 1979. Washington: International Food Policy Research Institute (IFPRI). https://doi.org/10.2499/p15738coll2.134179. 
Burgui, D. 2020. Coronavirus: How action against hunger is responding to the pandemic Available online at https://www.actionagainsthunger.org/story/coronavirus-how-action-against-hunger-responding-pandemic Accessed 16 July 2020.

CBN. 2020. CBN policy measures in response to COVID-19 outbreak and spillovers Available at : https://www. cbn.gov.ng/Out/2020/FPRD/CBN\%20POLICY\%20MEASURES\%20IN\%20RESPONSE\%20TO\% 20COVID-19\%20OUTBREAK\%20AND\%20SPILLOVERS.pdf Accessed 3 June 2020.

Ceballos, F., S. Kannan, and B. Kramer. 2020. Impacts of a national lockdown on smallholder farmers' income and food security: Empirical evidence from two states in India. World Development. 2020: 136. https://doi. org/10.1016/j.worlddev.2020.105069.

CGIAR. 2020. CGIAR's response to COVID-19 Retrieved online on 4/4/2020 at https://www.cgiar.org/newsevents/all-news/our-response-to-covid-19/.

Commodity Markets Outlook. 2020. A shock like no other: The impact of COVID-19 on commodity markets. Special focus Available online at http://pubdocs.worldbank.org/en/558261587395154178/CMO-April2020-Special-Focus-1.pdf.

Cooper, C.D., and N.B. Kurland. 2002. Telecommuting, professional isolation, and employee development in public and private organizations. Journal of Organizational Behavior 23: 511-532.

Delius, A., K. Himelein, and U.J. Pape. 2020. Conducting rapid response phone surveys to fill data gaps. Poverty and equity notes. Washington: World Bank Available at https://openknowledge.worldbank.org/ handle/10986/34300 Accessed 25 Dec 2020.

Devereux, S., C. Bene, and J. Hoddinott. 2020. Conceptualising COVID-19's impacts on household food security. Food Sec 12: 769-772. https://doi.org/10.1007/s12571-020-01085-0.

Ekweonu, C.L. 2020. Newspaper coverage of domestic violence against women during COVID-19 lockdown. Nnamdi Azikiwe University Journal of Communication and Media Studies. 1 (2): 1-14.

FAO. 2008. An Introduction to the Basic Concepts of Food Security. FAO, Rome, Italy.

FAO. 2020a. A battle plan for ensuring global food supplies during the COVID-19 crisis Accessed 4 Apr 2020 at http://www.fao.org/news/story/en/item/1268059/icode/.

FAO. 2020b. World food prices drop in February Accessed 20 Apr 2020 at http://www.fao.org/news/story/en/ item/1264796/icode/.

FAO. 2020c. COVID-19 pandemic - impact on food and agriculture Available online at http://www.fao.org/ 2019-ncov/q-and-a/en/ Accessed 1 July 2020.

FAO, IFAD, UNICEF, WFP \& WHO. 2019. The state of food security and nutrition in the world 2019 safeguarding against economic slowdowns and downturns Accessed online 6 Apr 2020 at https://www. unscn.org/en/news-events/recent-news?idnews=1978 Accessed 1 July 2020.

Farrell, P., A.M. Thow, J.T. Wate, N. Nonga, P. Vatucawaqa, T. Brewer, M. Sharp, A. Farmery, H. Trevena, E. Reeve, H. Eriksson, I. Gonzalez, G. Mulcahy, J.G. Eurich, and N.L. Andrew. 2020. COVID-19 and Pacific food system resilience: Opportunities to build a robust response. Food Security 12: 783-791. https://doi.org/ 10.1007/s12571-020-01087-y.

Government of Nigeria. 2020. Nigeria food and nutrition response plan for COVID-19 pandemic, April 2020 Available at https://reliefweb.int/report/nigeria/nigeria-food-and-nutrition-response-plan-covid-19pandemic-april-2020 Accessed 6 Apr 2020.

Harris, J., L. Depenbusch, A.A. Pal, R.M. Nair, and S. Ramasamy. 2020. Food system disruption: Initial livelihood and dietary effects of COVID-19 on vegetable producers in India. Food Security. 12 (4): 841851. https://doi.org/10.1007/s12571-020-01064-5.

High-Level Panel of Experts on Food Security and nutrition (HLPE). 2020. Interim issues paper on the impact of COVID-19 on food security and nutrition (FSN) Available online at http://www.ceigram.upm.es/wp-content/ uploads/2020/03/HLPE.-Impact-of-COVID-19-on-FSN-2020-03-24.pdf Accessed 7 Apr 2020.

Huff, A.G., W.E. Beyeler, N.S. Kelley, and J.A. McNitt. 2015. How resilient is the United States' food system to pandemics? Journal of Environmental Studies and Sciences 5 (3): 337-347.

Ilesanmi, O.S., M. Ariyo, and A.A. Afolabi. 2020. Domestic violence amid the COVID-19 lockdown: A threat to individual safety. Global Biosecurity 2 (1): 1-8.

Ilies, R., K.M. Schwind, D.T. Wagner, M.D. Johnson, D.S. DeRue, and D.R. Ilgen. 2007. When can employees have a family life? The effects of daily workload on work-family conflict and social behaviors at home. Journal of Applied Psychology 92 (5): 1368-1379.

ILO. 2020a. COVID-19 and world of work: Impacts and responses. Geneva: International Labour Organization.

ILO. 2020b. Social protection responses to the COVID-19 crisis: Country responses in Asia and the Pacific. Bangkok and Geneva: International Labour Organization.

Ivanov, D. 2020. Predicting the impacts of epidemic outbreaks on global supply chains: A simulation-based analysis on the coronavirus outbreak (COVID-19/SARS-CoV-2) case. Transportation Research Part E 136: 101922. https://doi.org/10.1016/j.tre.2020.101922. 
Kansiime, M.K., J.A. Tambo, I. Mugambi, M. Bundi, A. Kara, and C. Owuord. 2020. COVID-19 implications on household income and food security in Kenya and Uganda: Findings from a rapid assessment. World Development 137: 105199. https://doi.org/10.1016/j.worlddev.2020.105199.

Kogo, B.K., L. Kumar, and R. Koech. 2020. Climate change and variability in Kenya: A review of impacts on agriculture and food security environment, development and sustainability (in press).

Laborde, D. 2020. International food policy research institute food export restrictions during the Covid-19 crisis Available online at https://public.tableau.com/profile/laborde6680\#!/vizhome/ExportRestrictionsTracker/ FoodExportRestrictionsTracker Accessed 7 Apr 2020.

Laborde, D.D., W. Martin, J. Swinnen, and R. Vos. 2020. COVID-19 risks to global food security. Science 369 (6503): 500-502. https://doi.org/10.1126/science.abc4765.

Lopez-Ridaura, S., L. Barba-Escoto, C. Reyna, J. Hellin, B. Gerard, and M. van Wijk. 2019. Food security and agriculture in the Western highlands of Guatemala. Food Security 11 (4): 817-833.

Malhotra, A., S. Gosain, and O.A. El Sawy. 2005. Absorptive capacity configurations in supply chains: Gearing for partner- enabled market knowledge creation. MIS Quarterly 29 (1): 147-187.

Maritan, C.A. 2001. Capital investment as investing in organizational capabilities: An empirically grounded process model. Academy of Management Journal 44 (3): 513-531.

Martins, L.L. 2005. A model of the effects of reputational rankings on organizational change. Organization Science 16 (6): 701-720.

Matsungo, T.M., and P. Chopera. 2020. Effect of the COVID-19-induced lockdown on nutrition, health and lifestyle patterns among adults in Zimbabwe. BMJ Nutrition, Prevention \& Health 2020: 1-8. https://doi. org/10.1136/bmjnph-2020-000124.

McKibbin, W. 2020. What are the possible economic effects of COVID-19 on the world economy? Warwick McKibbin's scenarios Available at https:/www.brookings.edu/blog/up-front/2020/03/06/what-are-the-possibleeconomic-effects-of-covid-19-on-the-world-economy-warwick-mckibbins-scenarios/ Accessed 1 Apr 2020.

National Bureau of Statistics (NBS). 2020. Nigeria's consumer Price index (CPI) march 2020 Available online at https://nigerianstat.gov.ng/elibrary Accessed 22 Apr 2020.

NBS. 2019. Nigeria unemployment rate 2006-2018 Available online at https://tradingeconomics.com/nigeria/ unemployment-rate. Accessed 12 Apr 2020.

NBS. 2020. NBS: $51 \%$ of households reduced food consumption to cope with COVID-19 shocks Available at https://www.thecable.ng/nbs-51-of-households-reduced-food-consumption-to-cope-with-covid-19-shocks Accessed 8 Aug 2020.

NCDC. 2021. Number of COVID-19 confirm cases in Nigeria Available at: https://covid19.ncdc.gov.ng/ Accessed 3 Jan 2021.

Nicola, M., Z. Alsafi, C. Sohrabi, A. Kerwan, A. Al-Jabir, C. Iosifidis, and R. Agha. 2020. The socio-economic implications of the coronavirus pandemic (COVID-19): A review. International Journal of Surgery 78: 185193. https://doi.org/10.1016/j.ijsu.2020.04.018.

Nigeria budget office of the federation. 2013-2020. Nigeria: Budget document Available online at https://www. budgetoffice.gov.ng/index.php/resources/internal-resources/budget-documents. Accessed 18 July 2020.

Nigeria Centre for Disease Control (NCDC). 2020. An update of COVID-19 outbreak in Nigeria Available online at https://ncdc.gov.ng/diseases/sitreps/?cat=14\&name=An\%20update\%20of\%20COVID-19\% 20outbreak\%20in\%20Nigeria Accessed 8 May 2020.

Oguntayo, R., A.O. Popoola, R.S. Opayemi, O.R. Faworaja, and A.O. Olaseni. 2020. (2020), spousal violence in the era of Covid-19 lockdown: The implication of socioeconomic distress and contextual factors. Ilorin Journal of Economic Policy. 7 (3): 51-60.

Poudel, P.B., M.R. Poudel, A. Gautam, S. Phuyal, C.K. Tiwari, N. Bashyal, and S. Bashyal. 2020. COVID-19 and its global impact on food and agriculture. Journal of Biology Today's World 9 (5): 221. https://doi.org/ 10.35248/2322-3308.20.09.221.

PWC. 2020. Responding to the business impacts of coronavirus (COVID-19). PwC Nigeria report Available online at https://www.pwc.com/ng/en/covid-19.html Accessed 18 July 2020.

Rosales, G., and W. Mercado. 2020. Effect of changes in food price on the quinoa consumption and rural food security in Peru. Scientia Agropecuaria 11 (1): 83-93.

Schmidhuber, J., J. Pound, and B. Qiao. 2020. COVID-19: Channels of transmission to food and agriculture. Rome: FAOAvailable online at. https://doi.org/10.4060/ca8430en.

Siche, R. 2020. What is the impact of COVID-19 disease on agriculture? Scientia Agropecuaria 11 (1) Trujillo ene./mar 2020. Available online at. https://doi.org/10.17268/sci.agropecu.2020.01.00.

Sidor, A., and P. Rzymski. 2020. Dietary choices and habits during COVID-19 lockdown: Experience from Poland. The Journal of Nutrition 2020 (12): 1657.

Sobo, E.J., D.R. Simmes, J.A. Landsverk, and P.S. Kurtin. 2003. Rapid assessment with qualitative telephone interviews: Lessons from an evaluation of California's healthy families program \& Medi-Cal for children. American Journal of Evaluation 24 (3): 399-408. 
Stephens, E.C., G. Martins, M.V. Wijk, J. Timsina, and V. Snow. 2020. Editorial: Impacts of COVID-19 on agricultural and food systems worldwide and on progress to the sustainable development goals. Agricultural Systems 183: 102873. https://doi.org/10.1016/j.agsy.2020.102873.

Sturges, J.E., and K.J. Hanrahan. 2004. Comparing telephone and face-to-face qualitative interviewing: A research note. Qualitative Research 4 (1): 107-118.

Sumner, A., C. Hoy, and E. Ortiz-Juarez. 2020. Estimates of the impact of COVID-19 on global poverty. UNUWIDER working paper 2020/43.

Surico, P., and A. Galeotti. 2020. The economics of a pandemic: The case of Covid-19 Published by the Wheeler Institute for Business and Development on March, 23, 2020. Available online at https://icsb.org/ theeconomicsofapandemic/ Accessed on 4 Apr 2020.

Swinnen, J., and J. McDermott. 2020. COVID-19 and global food security. Washington: International food policy research institute (IFPRI). https://doi.org/10.2499/p15738coll2.133762.

The United Nations World Food Programme. 2020. World Food Programme gears up to support children left without meals due to COVID-19 school closures Available online at https:/www.wfp.org/news/world-foodprogramme-gears-support-children-left-without-meals-due-covid-19-school-closures Accessed 24 Apr 2020.

Today Nigeria Newspaper. 2020. Yemi Osinbajo: Nine million pupils benefitting from school feeding programme Available online at today.ng/news/nigeria/yemi-osinbajo-nine-pupils-benefitting-school-feeding-programme-165752 Accessed 20 Apr 2020.

Torero, M. 2020. Without food, there can be no exit from the pandemic. Nature. 580: 588-589. https://doi.org/ 10.1038/d41586-020-01181-3.

UNDP. 2020. COVID-19: Looming crisis in developing countries threatens to devastate economies and ramp up inequality Available online at https://www.undp.org/content/undp/en/home/news-centre/news/2020/ COVID19_Crisis_in_developing_countries threatens_devastate_economies.html Accessed 20 Apr 2020.

UN-Habitat \& WFP. $\overline{2020}$. Impact of COVID-19 on livelihoods, food security \& nutrition in East Africa: Urban focus Retrieved from https://unhabitat.org/sites/default/files/2020/08/wfp-0000118161_1.pdf Accessed 1 Sept 2020.

United Nations. 2020. Policy brief: The impact of COVID-19 on food security and nutrition Available online at https://namibia.un.org/sites/default/files/2020 06/sg_policy_brief_on_covid_impact_on_food_security.pdf Accessed 20 Apr 2020.

Welsh, T. 2020. WFP chief warns of 'hunger pandemic' as COVID-19 threatens food security. Devex (blog). April 22, 2020 Available at : https://www.devex.com/news/sponsored/wfp-chief-warns-of-hungerpandemic-as-covid-19-threatens-food-security-97058. Accessed 24 Dec 2020.

World Bank. 2020. Assessing the economic impact of COVID-19 and policy responses in sub-Saharan Africa. Africa's pulse. Washington: World Bank Group.

World Data Lab. 2019. The percentage of Nigerians living in extreme poverty could increase by 2030 Available online at the World Poverty Clock at https://worldpoverty.io/ Accessed 24 Apr 2020.

Zurayk, R. 2020. Pandemic and food security: A view from the global south. J Agric Food Syst Community Dev 9. https://doi.org/10.5304/jafscd.2020.093.014 Available Accessed 7 July 2020.

Publisher's Note Springer Nature remains neutral with regard to jurisdictional claims in published maps and institutional affiliations.

\section{Affiliations}

\section{Abiodun Elijah Obayelu ${ }^{1} \cdot$ Oluwakemi Adeola Obayelu $^{2} \cdot K$ Kamilu Kolade Bolarinwa ${ }^{3} \cdot$ Richard Akinwumi Oyeyinka ${ }^{3}$}

1 Department of Agricultural Economics and Farm Management, Federal University of Agriculture, Abeokuta (FUNAAB), Ogun State, Nigeria

2 Department of Agricultural Economics, University of Ibadan, Ibadan, Oyo State, Nigeria

3 Department of Agricultural Administration, Federal University of Agriculture, Abeokuta, Abeokuta, Ogun State, Nigeria 